Special issue of the 2nd International Conference on Computational and Experimental Science and Engineering (ICCESEN 2015)

\title{
Micro-Abrasion Wear Behavior of Thermal-Spray-Coated Steel Tooth Drill Bits
}

\author{
A. GÜNEN*
}

Iskenderun Tech. Univ., Faculty of Technology, Materials Engineering Department, Hatay, Turkey

\begin{abstract}
Wear behavior of four kinds of thermally sprayed coatings on steel tooth drill bits have been investigated by micro-abrasion wear test. The fixed ball micro abrasion wear test was applied for bare substrate and for thermal sprayed substrate of each sample. $\mathrm{SiC}$ and $\mathrm{Al}_{2} \mathrm{O}_{3}$ abrasive powders with grain size of $5 \mu$ m were used in the abrasion experiments. Ball rotational speed values of $140 \mathrm{rpm}$ and applied loads of 1,2 and $3 \mathrm{~N}$ were used. Experimental results show that the wear mechanisms of the coatings are micro-grooving and micro-rolling. Application of the coatings was found to have an influence on the wear mechanism of the samples. The results also indicate that wear resistance of thermally sprayed coatings can be correlated to porosity, hardness, plasticity, toughness, and cohesion properties of the coatings. In addition, wear resistance of the coated samples had increased in accordance with the increasing coating thickness.
\end{abstract}

DOI: 10.12693/APhysPolA.130.217

PACS/topics: 81.05.Bx, 82.35.Gh, 81.65.Kn

\section{Introduction}

Drilling process is performed by a number of techniques ranging from rotary to percussive drilling in very hard rock, medium hard rock and soft rock types. Both in rotary and percussive drilling systems drill performance is determined largely by the cost of drilling. The drill performance depends primarily on the choice of drill bit and then on how the drill bit is used. Therefore, a lot of drill bits have been designed for drilling industry. One of them is the three-cone bit. This bit is used widely to drill most of the oilfield wells. It usually has three bearing-supported rolling cones (Fig. 1) with teeth or cutters distributed in different geometrically controlled patterns over each cone. Cutter elements are made of hard faced steel (Fig. 1a) or are formed by pressed-in sintered tungsten carbide inserts (TCI) (Fig. 1b). Steel tooth drill bits (STDB), which are made of hard-faced steel are used more widely because they are cheaper than other types of drill bits. However, as is the case with all drill bits, STDB are exposed to highly abrasive rock and high velocity fluids that cause severe wear, erosion and corrosion in service, depending on the operating conditions [1-5].

In order to overcome this problem, and to reduce the cost per foot, surface modification techniques such as chemical vapor deposition (CVD), boron ion implantation [6-9], pulse-plasma deposition [10], laser surface modification [11], thermal spray techniques (TS) [12], etc., have been studied for protecting the drill bits against wear, fluid erosion and corrosion [6-8]. Some of these coating techniques, CVD, boron ion implantation and pulse-plasma deposition, are reported as not suitable for rock drilling applications due to thin thickness of the protective layer and its inferior bonding strength with the substrate. Amongst the above techniques the best one is the TS technique. TS technique is preferred due to its productivity, thicker coatings, simplicity,
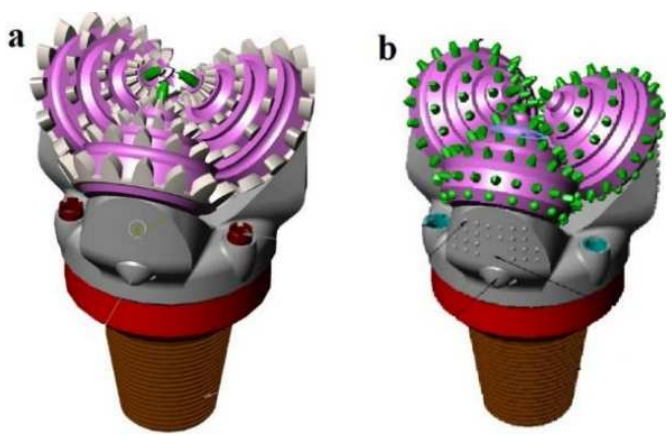

Fig. 1. Image of three-cone bits (a) STDB, (b) TCI.

robustness and cost effectiveness compared to other techniques. During the thermal spraying, powder particles are heated to molten or semi-molten state using flame spray (FS), plasma spray (PS) and high velocity oxygen fuel (HVOF). Depending on the thermal spray process used, powder particles can be accelerated to supersonic velocities, forming dense coatings with good wear and corrosion properties [13-15].

Although micro-abrasion is a common materialslimiting issue in industrial applications [16-18], most of the studies have been carried out in the field of microstructure properties, wear and corrosion resistance of thermally sprayed coatings. However, a little attention was payed in literature to the effects of micro-abrasion on wear and corrosion behavior [19-20]. Such effects are important to characterize, because micro-abrasion in rock drilling and industrial applications typically occurs in different tribo-corrosive environments. Understanding the micro-abrasion wear behavior of drill bits is critically important for improving the coating for rock drilling conditions. For this purpose in this article, the micro-abrasion wear performance of samples, thermal spray coated with four different coating powders, was assessed and compared to each other. 


\section{Materials and methods}

\subsection{Development of coatings}

The substrate material selected for the study was STDB samples with chemical composition given in Table I.

\section{TABLE I}

Chemical composition (wt.\%) of the STDB used in experimental studies.

\begin{tabular}{c|c|c|c|c|c|c|c}
\hline \hline Fe & $\mathrm{Ni}$ & $\mathrm{Mo}$ & $\mathrm{Cu}$ & $\mathrm{Si}$ & $\mathrm{Cr}$ & $\mathrm{Mn}$ & $\begin{array}{c}\text { Other elements, } \\
\text { Mo, } \mathrm{N}\end{array}$ \\
\hline 94.2 & 3.81 & 0.3 & 0.18 & 0.24 & 0.2 & 0.44 & 0.63
\end{tabular}

Specimens with dimensions of approximately $70 \times 20 \times$ $10 \mathrm{~mm}^{3}$ were prepared out of STDB and grit blasted with alumina powders (grit 45) before the deposition processes. The coating processes was performed by FS and HVOF techniques to examine the effect of different coating thicknesses and different coating powders. Commercial powders named $36 \mathrm{C}, 15 \mathrm{~F}$, Diamalloy 5849, and Diamalloy 3004 were used as coating materials. Flame spraying was carried out using a Metco $5 \mathrm{P}$ spray gun and for the HVOF application a Jetkote II system was used at DEKA Surface Technologies Company Pvt. Limited (Turkey). The chemical composition of the coating powders and the process parameters used in the coating processes are reported in Table II. All process parameters, including the spray distance, were kept constant throughout the coating processes.

TABLE II

HVOF and FS parameters during coating processes.

\begin{tabular}{c|c|c|c|c|c}
\hline \hline $\begin{array}{c}\text { Spray } \\
\text { process }\end{array}$ & Powder & $\begin{array}{c}\mathrm{O}_{2} \text { flow } \\
\text { rate/ } \\
\text { pressure } \\
{\left[\mathrm{m}^{3} / \mathrm{h}\right]}\end{array}$ & $\begin{array}{c}\text { Flow rate/ } \\
\text { pressure } \\
{\left[\mathrm{m}^{3} / \mathrm{h}\right]}\end{array}$ & $\begin{array}{c}\text { Powder } \\
\text { feed fate/ } \\
\text { pressure } \\
{[\mathrm{kg} / \mathrm{h}]}\end{array}$ & $\begin{array}{c}\text { Spray } \\
\text { distance } \\
{[\mathrm{mm}]}\end{array}$ \\
\hline FS & $36 \mathrm{C}$ & 1.5 & $\mathrm{C}_{2} \mathrm{H}_{2} 0.90$ & 5.0 & 200 \\
FS & $15 \mathrm{~F}$ & 1.8 & $\mathrm{C}_{2} \mathrm{H}_{2} 0.90$ & 7.5 & 200 \\
HVOF & Diamalloy 5849 & 1.8 & $\mathrm{H}_{2} 3.6$ & 3.6 & 150 \\
HVOF & Diamalloy 3004 & 1.8 & $\mathrm{H}_{2} 3.6$ & 3.6 & 150
\end{tabular}

\subsection{Characterization of FS and HVOF coatings}

For metallographic examinations, samples of appropriate size were cut and cross-sectional surfaces were cold mounted. The specimens were then grinded using 240, 320, 400, 600, 800, 1000 and 1200 grit abrasive papers and polished with $3 \mu \mathrm{m}$ alumina paste followed by polishing with $1 \mu \mathrm{m}$ diamond paste. Optical studies were carried out using a Huvitz HDS-5800 Digital metal microscope, equipped with 3D image analysis software. Scanning electron microscopy (SEM) studies were conducted using a TESCAN scanning electron microscope, equipped with energy dispersive spectroscopy (EDS) capability, at accelerating voltage of $25 \mathrm{kV}$. Microhardness measurements were recorded using a Future Tech FM700 hardness tester using $100 \mathrm{gf}$ load and $10 \mathrm{~s}$ dwell time. $\mathrm{X}$-ray diffraction (XRD) analyses were carried out using a computer-controlled Rigaku DMAX II RadB-XRD with $\mathrm{Cu} \mathrm{K}{ }_{\alpha}$ radiation, at $2 \theta$ angles ranging from $10^{\circ}$ to $80^{\circ}$.

\subsection{Micro-abrasion wear tests}

Fixed-ball micro-abrasion wear test was first introduced by Kassman et al. [21] and had became one of the widely used methods in determination of abrasive wear resistance of thin hard coatings [22-23]. In this method, a hardened steel ball is rotating by applying pressure either with the help of a load or under its own weight in an abrasive suspension. The method in which a ball is rotating via a rotating shaft and is applying pressure under its own weight to test part is called the "fixed ball" method. The ball used in this study was made of AISI 52100 steel and had a diameter of $25.4 \mathrm{~mm}\left(1^{\prime \prime}\right)$. Prior to each wear test, balls and surface of the samples were ultrasonically cleaned in acetone for $10 \mathrm{~min}$ and then air dried. Silicon carbide $(\mathrm{SiC})$ and alumina $\left(\mathrm{Al}_{2} \mathrm{O}_{3}\right)$ with the average particle size of $5 \mu \mathrm{m}$ were used as the abrasives. The abrasive slurry was created with the composition of 30 , 40 and $50 \%$ balance of distilled water. Rotational speed of the ball was selected as $140 \mathrm{rpm}$. Each test was repeated three times. In the course of these tests, a drop of abrasive slurry was applied every 20 seconds. The total test time for each sample was determined as 180 seconds.

\section{Results and discussion}

\subsection{Microstructural characterization}

Some properties, measured from the coating crosssections, are reported in Table III. Table III shows that

TABLE III

Some properties of coatings used in this study.

\begin{tabular}{c|c|c|c|c|c}
\hline \hline $\begin{array}{c}\text { Coating } \\
\text { name }\end{array}$ & $\begin{array}{c}\text { Coating } \\
\text { process }\end{array}$ & $\begin{array}{c}\text { Thickness } \\
{[\mu \mathrm{m}]}\end{array}$ & $\begin{array}{c}\text { Micro- } \\
\text { hardness } \\
{[\mathrm{HV}]}\end{array}$ & $\begin{array}{c}\text { Roughness } \\
{[\mu \mathrm{m}]}\end{array}$ & $\begin{array}{c}\text { Porosity } \\
{[\%]}\end{array}$ \\
\hline 1 & FS & 893.36 & 771.5 & 0.15 & 1.8 \\
2 & FS & 782.69 & 707.6 & 0.1 & 1 \\
3 & HVOF & 660.54 & 984 & 0.25 & 3.2 \\
4 & HVOF & 340.64 & 714 & 0.3 & 4
\end{tabular}

the hardness values, measured for all coatings produced by FS and HVOF, were ranging from 714 to $984 \mathrm{HV}_{0.1}$. This is significantly higher than the hardness of the bare substrate, measuring $<355 \mathrm{HV}_{0.1}$. It was found that the hardness of the tungsten carbide powders was higher than that of the chromium carbide powders. Such high hardness is expected to be favorable for wear-resistance applications. The highest micro hardness was obtained in WC-Co-Cr coating deposited by HVOF and the lowest hardness was obtained in $15 \mathrm{~F}$ deposited by flame spraying method. This can be attributed to the microstructure and phase formation of the hard phases, such as WC. In addition the thickness of the coatings had measured 
between the 893.36 and $340.64 \mu \mathrm{m}$, which is in accordance with many studies in the literature [12, 24, 25]. The measured surface roughness was $0.1-0.3 \mu \mathrm{m}$ and porosity of the coating had ranged between 1 and $4 \%$, which is in the acceptable range.

Figure 2 shows SEM image of the coatings produced by FS and HVOF. The coatings named 1, 2, 3 appear to be fully dense, however coating number $4\left(\mathrm{Cr}_{3} \mathrm{C}_{2}-25(\mathrm{Ni}-\right.$ $20 \mathrm{Cr})$ ) shows oxides, cracks and porosity in some regions. These are undesirable defects of the coatings which have to operate under tribo-corrosion conditions, since cracks and open porosities could expose the substrate to the aggressive environment, nullifying the protective function of the coating [26]. In such case the wear resistance of the coating decreases.
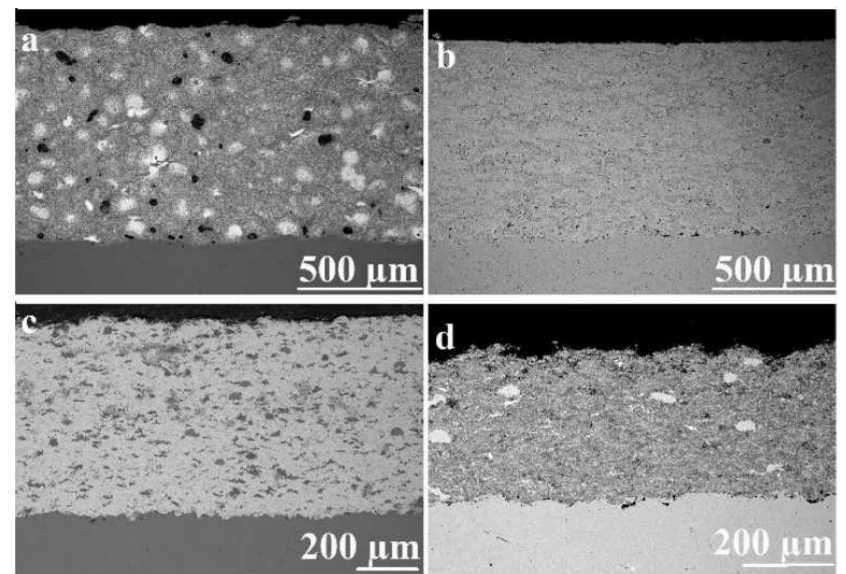

Fig. 2. SEM images of (a) 36C FS as-sprayed, (b) $15 \mathrm{~F}$ FS as-sprayed, (c) Diamalloy 5849 HVOF assprayed, (d) Diamalloy 3004 HVOF as-sprayed.

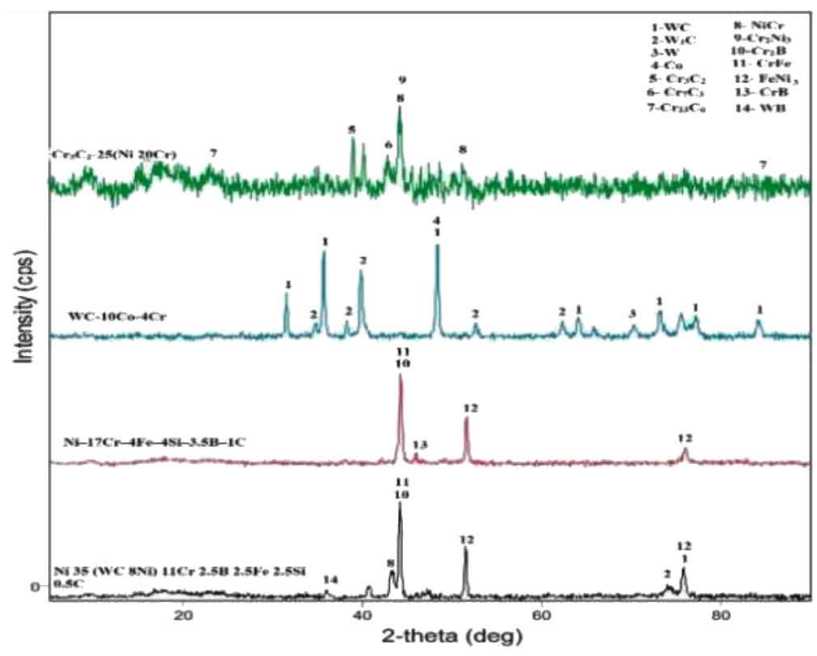

Fig. 3. XRD analysis of the coated samples.

Figure 3 shows the XRD analysis of samples coated by FS and HVOF. There have appeared different phases in the samples, depending on the chemical composition of the powders used. In the sample coated by WC-10Co$4 \mathrm{Cr}$ powder $\mathrm{WC}, \mathrm{W}_{2} \mathrm{C}, \mathrm{W}$ and Co phases were detected.
It is indicated by many researches that $\mathrm{W}_{2} \mathrm{C}$ is formed as a result of partial decarburization of tungsten carbide to di-tungsten carbide $[27,28]$. The XRD pattern for the assprayed $\mathrm{Cr}_{3} \mathrm{C}_{2}-25(\mathrm{Ni}-20 \mathrm{Cr})$ coating shows a diffraction pattern with a number of overlapping diffraction lines of carbides $\mathrm{Cr}_{3} \mathrm{C}_{2}, \mathrm{Cr}_{7} \mathrm{C}_{3}, \mathrm{Cr}_{23} \mathrm{C}_{6}$ and binder $\mathrm{NiCr}$, as was reported earlier [28]. The only difference from the previous study is the presence of $\mathrm{Cr}_{2} \mathrm{Ni}_{3}$ phase. It has been reported that decarburization of $\mathrm{Cr}_{3} \mathrm{C}_{2}$ to $\mathrm{Cr}_{7} \mathrm{C}_{3}$ or $\mathrm{Cr}_{23} \mathrm{C}_{6}$ does not have a detrimental effect on the wear resistance of the coating [29]. However, in case of WCbased coatings, the decomposition may deteriorate the wear properties of the coating due to the formation of brittle carbides and oxy-carbides [28, 30]. When examining the XRD diagrams of the coating produced by FS, it can be seen that boron (B) and iron (Fe), are effective in the phase formation. In these coatings boron and iron containing phases have been found, such as $\mathrm{CrB}$, WB, $\mathrm{FeNi}_{3}, \mathrm{CrFe}, \mathrm{Cr}_{2} \mathrm{~B}$.

\subsection{Micro-abrasion wear results}

Micro-abrasion prevails over many physical and chemical mechanisms acting on wear pairs during the wear process. Contact geometry, surface roughness, microstructural properties, grain size, toughness, speed, load, temperature, time and the environment are important parameters in the formation of wear mechanisms occurring on the surface of the wear pairs [31-33]. Volume losses after fixed-ball micro-abrasion wear test are given in Figs. 4 and 5. Wear tests were performed using $\mathrm{Al}_{2} \mathrm{O}_{3}$ and $\mathrm{SiC}$ abrasive powder under three different loads (1, 2 and $3 \mathrm{~N}$ ), at three different concentrations of abrasive powder $(30 \%, 40 \%, 50 \%)$ and at sliding rate of $140 \mathrm{rev} / \mathrm{min}$. In the calculation of the volume losses was used an equation from previous studies $[34,35]$. As it can be seen from the Fig. 4, the best wear resistance was obtained in specimen 1 . This was followed by specimens number 2 , 3 and 4 , respectively.

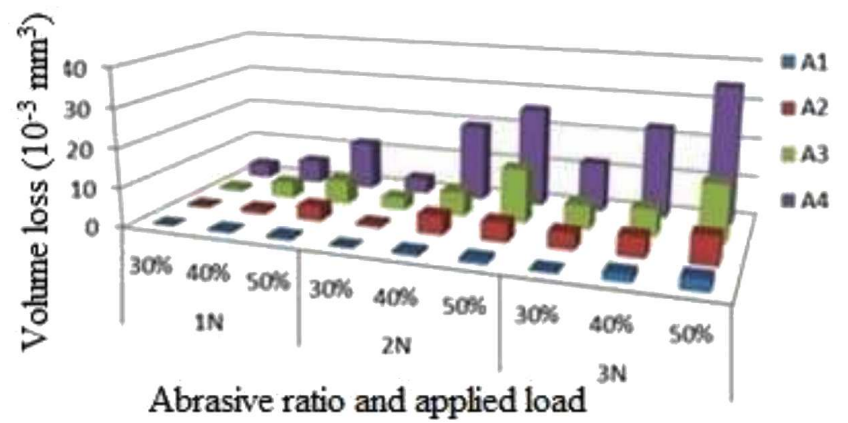

Fig. 4. Graph of volume loss under action of $\mathrm{Al}_{2} \mathrm{O}_{3}$ abrasive.

The micro-abrasion wear test performed in solutions containing $\mathrm{SiC}$, under the same conditions, are reported in Fig. 5. As can be seen from Fig. 5, volume loss of the samples subjected to wear process in $\mathrm{SiC}$ abrasive 


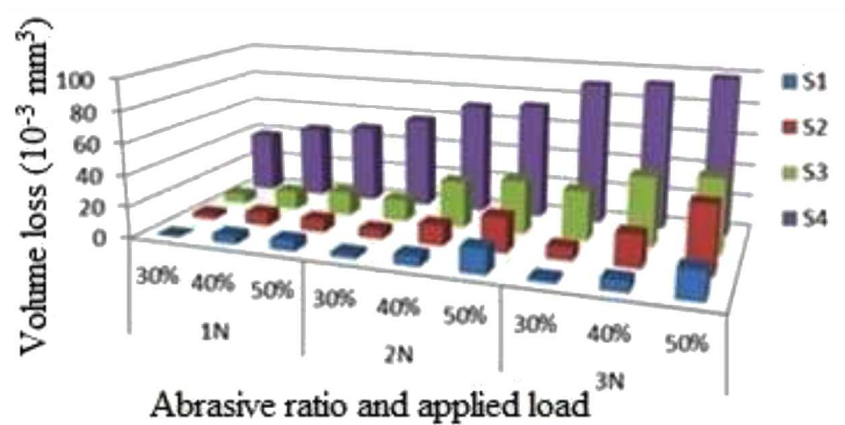

Fig. 5. Graph of volume loss under action of $\mathrm{SiC}$ abrasive.

solution was higher than that of the samples subjected to wear process in $\mathrm{Al}_{2} \mathrm{O}_{3}$ solution. This is closely related to the hardness of $\mathrm{SiC}\left(2900-3000 \mathrm{HV}_{0.3}\right)$ and $\mathrm{Al}_{2} \mathrm{O}_{3}$ (2200-2100 $\mathrm{HV}_{0.3}$ ).

When the volume loss of the samples was studied by taking into consideration the applied load, it was found that volume loss of the samples also increased with increasing load (Figs. 4 and 5). Increasing the load results in an increase of the pressure applied by the particles. Thus, a particle, trapped between the abrasive ball and the abraded surface, will penetrate deeper into the surface of the abraded material. Undoubtedly, one of the important parameters involved in this sinking process will be the volume hardness of the sample. An increase in the hardness of the sample will generally result in more resistance against surface indentation, so the penetration of abrasive particles will be reduced. However, the increase of the load on the particles will also increase their penetration. A particle, penetrated into surface, tears off the material from adjacent regions of surface by applying force to the material. The microstructure and micromechanical properties of the sample are of importance in this process. Particles, in the form of splat $30-40 \mu \mathrm{m}$ held to each other by plastic deformation, break with abrasive cutting effect from the weakest connected splat point. Thus metal transfer takes place from the surface. In addition, the increasing load on the abrasive particle will cause the fracture. So fractured abrasive particles, which have more sharp corners, will be another factor increasing the wear losses.

When volume loss of the samples is investigated as function of concentration of the abrasive, the increase in abrasive concentration results in an increase of the volume loss (Figs. 4 and 5). This is attributable to the amount of abrasive particle touching the material surface per unit time, because it is obvious that grinding motion to the abrasive particles, moved along the cutting surface by the ball, will abrade the surface and will lead to further volume loss.

Figure 6 shows SEM micrograph of the sample 1, subjected to the wear test at $1 \mathrm{~N}, 140 \mathrm{rpm}$, in $30 \% \mathrm{SiC}$ abrasive solution. It is seen that the circular-shaped abrasion marks are found to be compatible with those

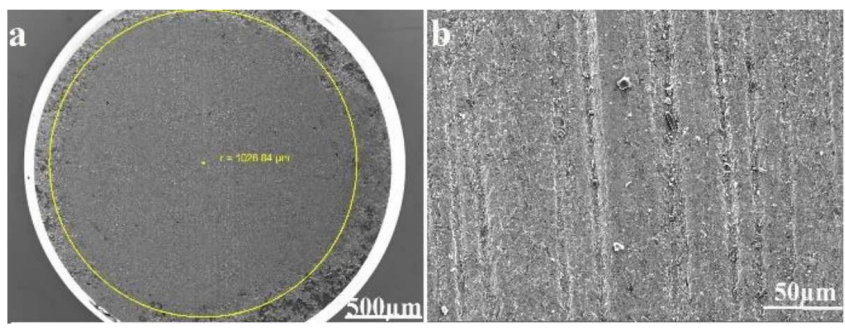

Fig. 6. SEM micrograph of the sample 1, subjected to the wear test at $1 \mathrm{~N}, 140 \mathrm{rpm}$ in $30 \% \mathrm{SiC}$ abrasive solution (a) $100 \times$, (b) $1500 \times$.

mentioned in ASTM G77 standard [36]. When this micrograph was examined at higher magnification, it was found that active micro-grooving is the type of abrasive wear at low concentrations (Fig. 6b).

Examination of Fig. 7a shows two regions $\mathrm{A}$ and $\mathrm{B}$. It can be seen that micro-grooving type of wear mechanism is predominant in area B (Fig. 7b). However, microrolling type of wear is also present in the system (Fig. 7b). Whereas in the area A (Fig. 7c) the micro-rolling type of wear mechanism is predominant.

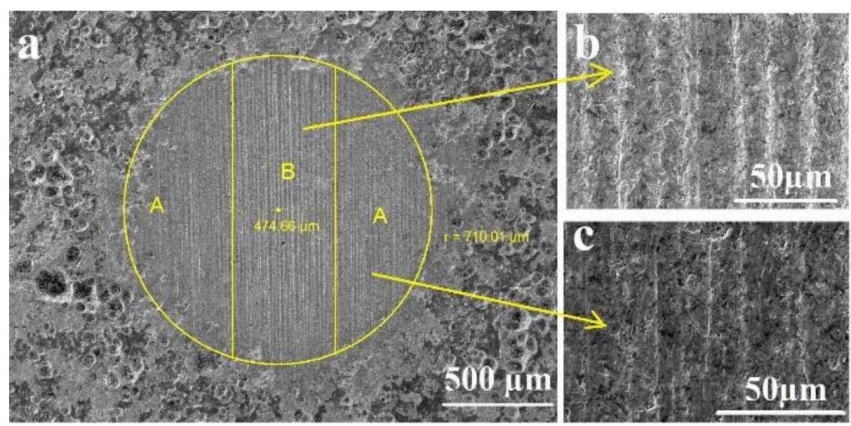

Fig. 7. SEM micrograph of the sample 2, subjected to the wear test at $1 \mathrm{~N}, 140 \mathrm{rpm}$ in $50 \%$ abrasive solution (a) $110 \times$, (b) $1000 \times$, (c) $250 \times$.

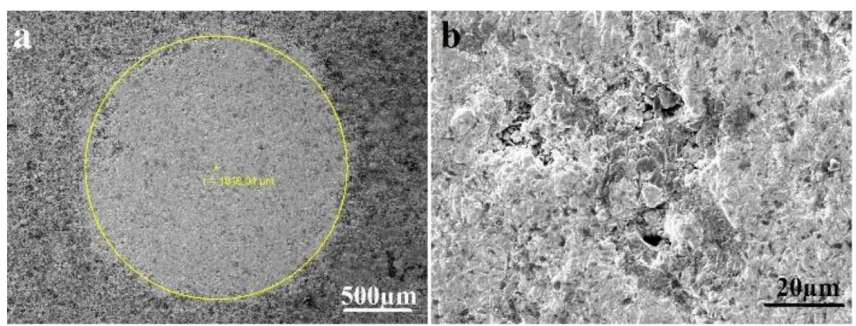

Fig. 8. SEM micrograph of the sample 3, subjected to the wear test at $1 \mathrm{~N}, 140 \mathrm{rpm}$ in $40 \%$ abrasive solution (a) $85 \times$, (b) $2500 \times$.

SEM microstructures of coating produced by $\mathrm{HVOF}$ are given in Figs. 8 and 9. It is observed that wear mechanism has completely changed in the sample produced by HVOF method.

It is seen that the wear mechanism is entirely of microrolling type (Figs. 8 and 9). This is related to microstructure of the samples. Sample 3, has the highest vol- 


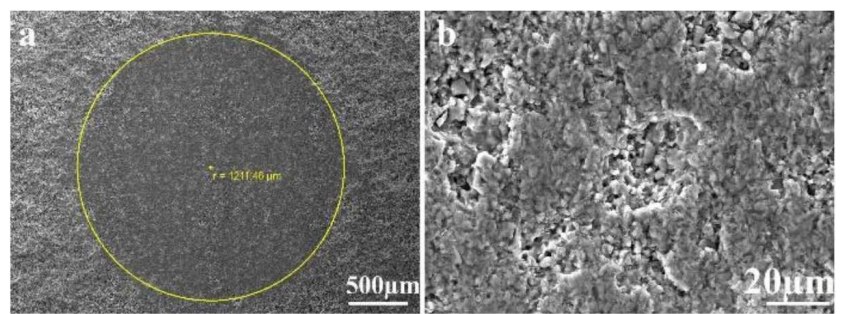

Fig. 9. SEM micrograph of the sample 4, subjected to the wear test at $1 \mathrm{~N}, 140 \mathrm{rpm}$ in $50 \%$ abrasive solution (a) $75 \times$, (b) $2000 \times$.

ume hardness among all studied samples. An increase in the hardness of a material will result in a decrease in its toughness. The decrease in fracture toughness of the material will lead to the increased fragility. When Fig. 9 is examined, fractures with sizes of $10-20 \mu \mathrm{m}$ are seen, comparable with the abrasive particle size, which is associated with nullifying the protective function of the coating.

\section{Conclusions}

In this study, wear behavior of four kinds of thermally sprayed coatings on steel tooth drill bits have been investigated by micro-abrasion wear test. Main results can be summarized as follows:

1. The morphology of coating was in the acceptable range. The coatings have no cracks, are homogeneous, dense, with low amount of oxides, and low porosity.

2. Microstructure and hardness of the samples plays an important role in the formation of wear mechanisms.

3. Increasing in abrasive concentration and increasing the applied load result in the increase of the volume loss.

4. While generally grooving was the main wearing mechanism in region where the ball and the eroded surface were in heavy interactions, in other sides the rolling type of wear mechanism has been effective.

5. Wear resistance of the coated samples had increased in accordance with the increasing coating thickness.

\section{Acknowledgments}

This study was supported by the TUBITAK Research Council (Project No: 213M629). The authors wish to thank DEKA Surface Technologies Company Pvt. Limited (İzmir/Turkey) and Kemal Demirkurt for the contributions to this study.

\section{References}

[1] P.X. Moore, Drilling Practices Manual, 2nd ed., PennWell Publishing Company Oklahoma, USA 1986 , p. 363.

[2] R.E. Grimes, E.C. Felderhoff, H. Brown, Oil Gas J. 18, 76 (1992).

[3] R.A. Bobo, J. Petr. Tech. 20, 700 (1968).

[4] K.W. Cummins, Technical Report No 28, Michigan State Univ. Inst. of Water Research, 1973.

[5] D. Praillet, World Mining Equipments Sept., 20 (1998).

[6] K. Teii, T. Hori, S. Matsumoto, Thin Solid Films 519, 1817 (2011).

[7] I. Mrochek, R. Gunzel, W. Matz, W. Moller, V. Anishchik, Nukleonika 44, 217 (1999).

[8] L.D. Yu, G.W. Shuy, T. Vilaithong, Surf. Coat. Technol. 128-129, 404 (2000).

[9] A. Kolitsch, E. Richter, Cryst. Res. Technol. 18, 5 (1983).

[10] M.J. Kupczyk, P. Siwak, J. ASTM Int. 8, 1 (2011).

[11] N.J. Kar, IADUSPE Drilling Conj., 1990, p. 49.

[12] M.W. Richert, B. Mikułowski, P. Pałka, A. Hotloś, M. Perek-Nowak, J. Surf. Eng. Mat. Adv. Techn. 3, 1 (2013).

[13] P. Fauchais, A. Vardelle, in: Advanced Plasma Spray Applications, Ed. H. Jazi, InTech, 2012.

[14] A.C. Karaoglanli, Sci. Adv. Mater. 7, 173 (2015).

[15] A.C. Karaoglanli, B. Demirel, A. Turk, R. Varol, K.M. Doleker, Appl. Surf. Sci. 354, 314 (2015).

[16] R.I. Trezona, D.N. Alsopp, I.M. Hutchings, Wear 225, 205 (1999).

[17] M.M. Stack, M. Mathew, Wear 255, 14 (2003).

[18] M.M. Stack, H. Jawan, M.T. Mathew, Tribol. Int. 9, 848 (2005).

[19] M.M. Stack, M. Mathew, C. Hodge, Electrochim. Acta 56, 8249 (2011).

[20] A.C. Karaoglanli, Materials Technol. 49, 253 (2015).

[21] A. Kassman, S. Jacobson, S. Erickson, P. Olsson, M. Hedenqvist, Surf. Coat. Technol. 50, 75 (1991).

[22] X.Z. Ding, C.T. Bui, X.T. Zeng, Surf. Coat. Technol. 203, 680 (2008).

[23] A. Günen, M.S. Gök, A. Erdoğan, B. Kurt, N. Orhan, Tribol. Trans. 56, 400 (2013).

[24] K.T. Kembaiyan, K. Keshavan, Wear 186-187, 487 (1995).

[25] G. Bolelli, L. Lusvarghi, R. Giovanardi, Surf. Coat. Tech. 202, 4793 (2008).

[26] R. Pileggi, M.M. Tului, D. Stocchi, S. Lionetti, Surf. Coat. Tech. 268, 247 (2015).

[27] D.A. Stewart, P.H. Shipway, D.G. McCartney, Acta Mater. 48, 1593 (2000).

[28] J.K.N. Murthy, B. Venkataraman, Surf. Coat. Tech. 200, 642 (2006).

[29] P. Vuoristo, K. Niemi, A. Makela, T. Mantyla, Proc. 7th National Thermal Spray Conference, Boston, Massachusetts, 1994, p. 121.

[30] A. Karimi, Ch. Verdon, Surf. Coat. Tech. 57, 81 (1993). 
[31] H. Sin, N. Saka, P. Suh, Wear 55, 163 (1979).

[32] D.L. Duan, S. Li, X.H. Duan, Z.S. Li, Tribol. Trans. 48, 45 (2005).

[33] M.S. Gok, Y. Kucuk, V. Koc, O. Gencel, W. Brostow, Mech. Adv. Mater. Struc. 18, 389 (2011).

[34] K.I. Schiffmann, R. Bethke, N. Kristen, Surf. Coat. Techn. 200, 2348 (2005).
[35] I.M. Hutchings, Tribol. Intern. 31, 5 (1998).

[36] ASTM G77-05 Standard Test Method for Ranking Resistance of Materials to Sliding Wear Using Blockon-Ring Wear Test (2010). 